\title{
The Research of Reliability and Validity on Computer Courses Network Test System
}

\author{
Xia Yaowen \\ Institute of Information \\ Yunnan Normal University \\ Kunming,Yunnan Province,China \\ xywen_km@sina.com
}

\begin{abstract}
At present the network examination system reliability and validity of the study is less, based on the experimental approach from the test system, the user's point of view on the reliability and validity of the theoretical analysis and case research, network test system for the further development of the attempt to put forward some reference opinions in the future, in order to network test system more perfect, more scientific test students practical ability, promoting teaching reform, improve the education quality, and at the same time, this study also is helpful to enrich and promote the development of the theory of education technology subject.
\end{abstract}

Keywords- Network Test System,The Experiment Design,Correlation Coefficient,Reliability, Validity

\section{INTRODUCTION}

At present the network examination system research a lot, but more research is focus on the design and the development of the test system, the lack of this kind of exam system reliability and validity, and to test system users, the test system reliability and validity is the focus of attention, they only high reliability and high efficiency degree evaluation tool to objectively and correctly reflect the true level of the estimator and practical ability.

\section{RELIABILITY AND VALIDITY THEORY OVERVIEW}

\section{A. Reliability meaning}

Reliability is simply a measured data and conclusions of the reliability degree, which is measuring tool, can steadily measurement to it to measure the degree of the matters. Reliability is reflect the stability and reliability of the measurement results of an important indicator, measuring reliability refers to the consistency of the measurement result degree, also called reliability level (i.e. multiple measurement results the same or consistent), includes two meanings: one is to use the same test of repetitive measure a lasting characteristic, if you can get the same result, namely measurement scale is stable, reliable, The second is test can reduce the influence of random error, and can provide to the measurement of a characteristic of the truth[1].

The reliability of the test: Test reliability, is a group of the test results on the same group and the implementation of the multiple test another group of the consistency of the performance level. The higher the degree of consistency, the test is more reliable, more credible, reliability is higher. If a test get is completely reliable true score (on behalf of the real level of fraction), not because of the papers of the sampling and shows the errors caused by, not because of anxiety, tension, fatigue, environmental or other influence factors of the results from error, not because of marker relies error and bias brought about by the error, so the test is complete and reliable, the test reliability coefficient is 1 , of course, any exams are inevitably have error, the test reliability is above 0.9 is perfect for you.

Test reliability: it means the whole roll each item consistency degree, also is the internal consistency reliability test. If the proposition is good, high quality, students score reflects the students' real situation, this paper reliability is high, and paper reliability is low.

\section{B. $\quad$ Validity meaning}

Validity is the degree of accuracy, also called accuracy. It refers to the test that can detect it to measure the degree of the characteristics or function. Measuring tool is the extent to which we want to measure the true meaning of the concept, validity is higher, it indicates that the measurement result can show to the object of measurement of the real features. Measurement validity refers to the degree of the validity of measurement results, and is measured to the quality and quantity of the interviewers and to measure quality and quantity of the degree of consistent.

Test validity: validity is standardized test the necessary conditions, is an established goal to realize the degree of success, the test validity is targeting a certain test purpose or be measured in terms of the characteristics of the. Calculus for test questions of science and engineering university students' mathematics knowledge and skills is effective, the general junior high school students speaking is invalid. No effective degrees or low degree examination has no value, if a test can reflect the content and the corresponding ability level, and to a certain degree, that is to say the purpose of the test accurately measured it to measuring results, so the test is high degree [2].

Paper validity: refers to a test can effectively measure of students' practical study level degree, test validity reflects the accuracy of test. A good test should be real reaction students' actual level, usually result has always been good, when test score should be high, but usually learn bad when the exam score should be low. 


\section{The relationship of reliability and validity}

Reliability and validity is any kind of education scientific research two related important standard. The reliability of the results about the study consistency of stability evaluation is standard. A reliable research program, whether the process is who operation, or how many times the same operation, the result is always very consistent. Validity is a research program of the nature and function, but also of the correctness of the results of the study evaluation standard, a valid research program, not only can make a definite answer research and interpretation of the results of the study, but also to ensure that the results of the study in certain scale in the field of promotion. The role of the two combined look, reliability and validity is an education scientific research activities and results with scientific value and significance of the guarantee.

Reliability for validity is necessary but not sufficient condition, reliability does not guarantee a certain degree of effective, a reliable research program does not prove that the content must be effective, and a valid research must be a reliability study. Effective degree must have reliability, validity; reliability is the purpose of reliability is the basis of validity. Reliability is low, validity may not high, High reliability, validity is not necessarily high; Validity is low, the reliability is likely to high; High validity, reliability will high. Test the reliability and validity of has the close relation.

At present the reliability and validity of the theory is relatively mature, it with true score as the theoretical basis, although have some limitations, but is easy to understand, so is widely used in statistical analysis of the papers.

\section{NETWORK EXAM SYSTEM}

\section{A. Overview of network exam system}

The information age requires new test way, computer and network technology to promote the development of the network examination system generation and development. "Network test system is designed based on the Internet technology, the use of a computer to fast operation characteristics, high efficiency; using modern high-tech means to test a software system. Common with a function can be customized according to the requirements of the test paper to meet the requirements of automatic generation of test paper, the answer on a computer, submit the test paper test system can quickly grade papers, automatic complete examination paper analysis and statistics. Network test system with high quality papers and test resources as the foundation, to grasp of knowledge as the basis, through the intelligent and paperless examination means, reduce the burden on teachers' teaching, arouse the enthusiasm of students' autonomous learning, so as to achieve the aim at improving quality of teaching, and completely in the face of the candidate and opening up, the candidate be completely free main body, get rid of the bondage of traditional test model, reflect the real open[3][4].

\section{B. Computer courses network test process}

Online exam system of the background is the education informatization trend and education in colleges and universities information system construction; Purpose is to make full use of existing school of computer software and hardware resources and the network resources to achieve paperless examination. The basic flow test as shown in figure 1 shows:

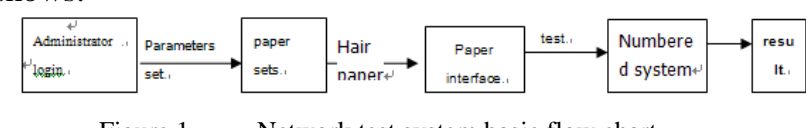

Figure 1. Network test system basic flow chart

In the test, ahead of management personnel login first test server, according to the examination requirements, set all kinds of group of volume parameter (the topic, the topic quantity, the test time, etc.), the system can automatically test from the extraction, conform to the requirements of the generating sets one or more papers, and your test paper automatic distributed to each table test machine. Candidates into the examination room examining interface login registration, the test answers, and the test after completion of the initiative can submit answers[5].

\section{NETWORK TEST SYSTEM RELIABILITY AND VALIDITY OF THE STUDY}

In the test process, the question of the reaction is a complicated internal psychological activity process, it is up to the actual level, motivation attitude and situational conditions and so on the many kinds of factors have common decision, so students own physical condition and mental also has certain influence on the exam. At the same time test environment, invigilation teacher, paper topic and proportional allocation, the investigation of methods for students' performance impact, then affects examination system reliability and validity[6]. But the physical and physiological, the test environment as long as make effective control, can be as much as possible to reduce the reliability and validity of the effect. The same hardware may also be on the system reliability and validity of the impact, but the hardware problems, such as wire speed, the computer configuration can through the update or upgrade the configuration can be solved, the minimum impact. Boil down to see, the test system group volume and score will be on the system reliability and validity have a direct impact. In the above consideration, this paper also mainly analyzes group roll, scoring rules this two parts. In this paper the examination system reliability research mainly from the test reliability, believe degree of examination paper and scoring reliability three aspects to carry on the analysis, The examination system validity research mainly from the test validity and test validity two aspects.

In any study, the influence factors are variables are represented. Variable names and variable division have different book differences, this research mainly reference YuanZhenGuo., higher education press by the education research methods, "a book classification of variables. Independent variables in the experiment is to control and the amount of change; The dependent variable is the amount of change with the independent variable; Organic variables are used to say that research of individuals in the innate characteristics, it is not a randomly assigned to individual 
variables, such as gender and intelligence; Intermediate variable can be inferred the existing variable, but it can't be controlled or measurement, its influence can only from the study of the relationship between the dependent and independent variables and deduced; Control variable is a variable other than play the leading role of the independent variables, and its effects are determined by the researcher control. In this paper the network examination system reliability study (mainly inspects the system automatically sets of test quality) variable divided as is shown in table 1:

TABLE I. NETWORK TEST SYSTEM RELIABILITY RESEARCH VARIABLES

\begin{tabular}{|l|l|}
\hline argument & paper \\
\hline Control variable & $\begin{array}{l}\text { Group volume method, the topic, the topic } \\
\text { quantity, class, students }\end{array}$ \\
\hline Organic variable & Gender, computer operation proficiency \\
\hline Intermediate variable & $\begin{array}{l}\text { The implementation of the hardware } \\
\text { environment, software environment, try to } \\
\text { physical and mental characteristics, invigilation }\end{array}$ \\
\hline Dependent variable & Student test scores (grade and test scores) \\
\hline
\end{tabular}

Network test system validity (mainly inspects the system automatically scoring rules of the criterion related validity) in the study of variable divided as shown in table 2:

TABLE II. NETWORK TEST SYSTEM VALIDITY RESEARCH VARIABLES

\begin{tabular}{|l|l|}
\hline argument & $\begin{array}{l}\text { Quandary way (artificial quandary, the system } \\
\text { automatically numbered) }\end{array}$ \\
\hline Control variable & $\begin{array}{l}\text { Test, test the number, class, school scale, time interval, } \\
\text { and grades }\end{array}$ \\
\hline $\begin{array}{l}\text { Organic } \\
\text { variable }\end{array}$ & Gender, computer operation proficiency \\
\hline $\begin{array}{l}\text { Intermediate } \\
\text { variable }\end{array}$ & $\begin{array}{l}\text { The implementation of the hardware environment, } \\
\text { software environment, try to physical and mental } \\
\text { characteristics, invigilation }\end{array}$ \\
\hline $\begin{array}{l}\text { Dependent } \\
\text { variable }\end{array}$ & Student test scores (grade and test scores) \\
\hline
\end{tabular}

Although different experimental design by different purposes, but can say, the design of the most important function is to control variation. The experimental variation mainly includes three aspects: system variation has nothing to do with variation and error variation. Experiments to try to make system variable benefit, control, not variation error variation minimum. Make the system variation benefit, also is to select the right argument level, make the independent variable levels of change in the dependent variable can be reflected. Independent variable control refers to the influence of the dependent variable is what irrelevant variable control, such as sample internal factors, age, professional, learning, fatigue, psychology and so on, also may be the external factors, such as the environment, requirements, etc. Education research is often used to control the principle of random variation has nothing to do. Make error variation minimum, error variation from the experiment of random fluctuations, direct source is a sample internal difference, such as the attitude, emotion, etc.; another source is measurement error. This kind of error by increasing the reliability of the measurement and under control, such as usually arrange appropriate experimental environment, the correct measuring method USES and so on.

\section{CONCLUSIONS}

Network test system can boast of time, space, glory glory on the regional assessment, it automatically identify candidates level, automatic group roll, automatic marking, automatic analysis and automatic learning are suggested, etc., can reduce teachers' work burden but also reduce the education investment, improve the teaching quality and quantity of one of the most effective means, its high efficiency, convenient and other advantages will make it widely used. The current network test system is present integration, intelligence, and personalized, diversified development trend.

\section{ACKNOWLEDGMENT}

This work is supported by the National NSF of China (No.60903131), the key project of the Education Bureau Youth Fund of Yunnan Province (No.07Z1066).

\section{REFERENCES}

[1] Yuan Zhenguo, Ed., education research method, higher education press in July 2000 the first edition.

[2] Zhang Hou,Xu Jianping "modern psychology and education statistics, Beijing normal university press, 2008, June 11 times.

[3] Sun Guoquan.examination paper analysis system [D] college of jilin university 2006.12

[4] Zheng Jinting university examination paper analysis system of research and development of east China normal university 2007.5.

[5] Yang Yang, Su He , exams quality analysis system[J]. application Inner Mongolia medical journals in December 2005

[6] Lin Kexue, XiaoDongRong result analysis and test quality quantitative assessment system[J]. changsha railway university (social science edition) 2003.9 